\title{
A utility theory approach for insurance pricing
}

\author{
Mohsen Gharakhani ${ }^{\mathrm{a}^{*}}$, Fatemeh Nasiri ${ }^{\mathrm{b}}$ and Maysam Alizadeh ${ }^{\mathrm{c}}$
}

${ }^{a}$ Department of Engineering, Qom University, Qom,

${ }^{b}$ Actuarial Science department, Eco Colledge of Insurance, Allameh Tabatabaie University, Tehran, Iran

${ }^{c}$ Computational Social Science Program, Department of Computational and Data Science, George Mason University, Fairfax, VA, USA

CH R O N I C L E

Article history:

Received December 5, 2015

Received in revised format

February 162016

Accepted March 182016

Available online

April 82016

Keywords:

Insurance pricing

Deductible

Premium Discount

Utility theory

Franchise

\section{A B S T R A C T}

Providing insurance contract with "deductible" is beneficial for both insurer and insured. In this paper, we provide a utility modeling approach to handle insurance pricing and evaluate the tradeoff between discount benefit and deductible level. We analyze four different pricing problems of no insurance, full insurance coverage, insurance with $\beta \%$ deductible and insurance with a D-dollar deductible based on a given utility function. A numerical example is also used to illustrate some interesting results.

\section{Introduction}

One of the essential responsibilities of insurance firms is to make up an insured for an incurred loss. When an insurance policy is issued, there are some arrangements between policyholder and insurance firm for the amount of compensation. The insured may collect the full cover in exchange of a bigger premium, that is, he may be compensated thoroughly as a result of the occurrence of the special covered event. Basically, another alternative may exist for insured to keep some part of loss, known as franchise or some kind of deductible, and collect a premium discount instead. Most of the insurance policies have a deductible clause which indicates that the insurer would pay a loss after deduction of insured's share. This practice could be appealing for both insurer and insured. Since the administration expenses of an insurance firm specially for settling a claim is normally high, and most of the claims are negligible, the insurer may disregard many of its claims from settling process and save significant amounts of manpower of claim staffs through applying deductible. This may reduce the overall expense of executing business for an insurance firm. The other advantage for the insurer is that the overall expense of losses reduces because the insured is aware that in the event of a loss he/she needs to pay his/her

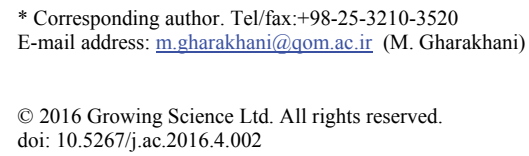


own share of loss, so he/she will do his/her best to stop the occurrence. Using deductible may influence on the frequency and severity of loss and control the probability of moral hazard. On the other side, "low risk" insureds may buy insurance policy to manage their risks and budget constraint, at the same time, by keeping some part of losses, they have the chance to reduce expenses of the insurance, called premium. Specifically, this is the case for an insured with individual large commercial risk which ought to pay substantial amount of premium. Therefore, the economic theory implies that many insureds would not require to insure small risk of the deductible if the cost is bigger than the actuarially fair cost, and therefore will more likely buy insurance with a deductible (Barniv et. al., 1999)

Many studies have examined optimality of deductibles in different optimal insurance settings, attempting to extend the original model of Raviv (1979) (Schlesinger, 1981; Doherty \& Schlesinger, 1983; Huberman et al., 1983; Karni, 1983; Blazenko, 1985; Gollier, 1987; Gollier, 1996; Gollier \& Schlesinger, 1995, 1996; Gollier, 2004; Dana \& Scarsini, 2007). Eecckhoudt et al. (1991) studied the dependence of optimal deductible on the distribution of losses.

The subject of studying deductible level in the insurance contracts has been attracted so much efforts of many researchers in the area of the insurance industry. Arrow (1965) and Raviv (1979) showed that the optimal form of risk retention could be achieved based on a straight deductible in an insurance contract on aggregate wealth. Arrow $(1974,1971)$ and Raviv (1979) stated that the insured may not often be willing to purchase the full coverage, since the premium could not actuarially fair and proved that the optimal policy for an insurance buyer would be the one who gives complete coverage, beyond a fixed deductible. Borch (1975) surveyed some issues faced in locating the optimal insurance coverage in which he/she discussed about locating the optimal insurance through detecting the optimal deductible using Arrow assumptions. Raviv (1979) examined Pareto optimal insurance contracts which ex-post insurance costs $\mathrm{C}$ and indemnity of $I$ that the necessary and sufficient conditions for the Pareto optimal deductible to be equal to zero is $C^{\prime}(I)=0$ for all $I \geq 0$.

Since the existence of deductible needs the insured to pay his share of the loss, Shavell (1979) combined the deductible with moral hazard emphasizing on attempt of the insured for preventing loss and controlling its effects. Dréze (1981) estimated the optimal level of deductible in an insurance policy which is decreasing with risk aversion in a range $[1,4]$ for relative risk aversion. He also concluded that the optimal level of deductible should be somewhere between $6 \%$ and $23 \%$ of the total wealth of the policyholder.

Schlesinger (1981) studied the problem of optimal deductible in insurance policies and explained that it had strong relationship with degree of risk aversion. Doherty and Schlesinger (1983) investigated the problem of optimal deductible in insurance contracts when the initial wealth was random, whereas Demers and Demers (1991) surveyed the effect of increasing risk on optimal deductible for both riskaverse insureds and risk neutral ones. Meyer and Ormiston (1999) studied various aspects of insurance demand associated with deductible insurance and resolved important issue concerning analysis of the optimal deductible through a simple sufficient restriction on pricing of insurance to ensure reaching the second order condition for selecting the expected utility maximizing deductible level. The main contribution of their paper was to determine sufficient assumptions on the decision model to meet the second order condition for selecting the expected utility maximizing deductible level for all risk aversion decision makers.

Barniv et al. (1999) analyzed the effect of wealth on deductible's demands for the flood insurance in both theoretical and practical context. They concentrated on the relationship between wealth of policyholder and the amount of selected deductible. Chitgopekar (2000) examined the effect of various types of deductible on expected payouts assuming an exponential function for loss. He provided a proper guidance for insured to choose the level of deductible and for the insurer to determine the amount of deductible. Gollier (2002) investigated a dynamic model of insurance with a liquidity constraint 
along with the optimal deductible and reported that the insurance might only be demanded for catastrophic risks, or by those with liquidity constraint.

Kunreuther and pauly (2006) recognized "preference for low deductible" as an anomalies on the demand side based on a positive model of choice and proposed an explanation as to why they happen. They also stressed that individuals are often interested in having low deductibles, while the lower deductible leads to higher chance for the insurance company to make some payments in the future in exchange for their premium contribution. They described other anomalies in demand for insurance which relates to deductibles. Aase (2010) further developed the work of Raviv (1979) and applied Pareto optimal deductible and described when the claim is relatively small, it is not optimal for the insured to receive compensation since the expenses outweighs the advantages and a deductible condition naturally happens.

Many papers in the context of insurance demand concentrated on the optimality of deductible level and its response to change in wealth with special attention to its impacts on the price of insurance. However, none of the afore-mentioned papers investigated the relationship between the premium discounts which the insurer is permitted to offer to the policyholder against given deductible regarding the lower bound for premium discount. Therefore, an important unresolved question within all of those efforts about the insurance demand in utility context requests what percentage of discount in the chargeable premium could be assigned to insured in exchange for reimbursing given amount/percentage of any loss for all risk-averse decision makers. On the other words, how much premium discount is sufficient for riskaverse decision makers to satisfy them with a given deductible level? The solution for this problem would influence on the performances of insurance firms in properly determining various levels of premium discount in order to acquire insurance consumers which subsequently influences on the insurance demands for an insurer and its respective market share.

Our main contribution in the current paper is to investigate the problem of determining the relationship between deductible level and premium discount through insured's expected utility function. We first try to model the problem using utility theory and find the relationship between these two important factors i.e. deductible and premium discount. The paper proceeds as follows. First, the notations and assumptions are introduced and insured's utility function is restated for two cases of buying and not buying insurance. Second, the limits for premium which the insured agrees to pay are calculated. Then, considering the utility function for insured in condition of buying insurance with paying $\beta \%$ deductible and receiving $\alpha \%$ discount in premium, the relationship between $\alpha$ and $\beta$ will be calculated. Next, the same calculation will be performed for the case of accepting to pay D-dollar deductible and receiving the same $\alpha \%$ of premium discount. Finally, using a popular utility function for insured, we investigate several models with a numerical example.

In the next section, for the purpose of clarification, we will review two popular kinds of deductibles.

\subsection{Different types of deductibles}

In the context of insurance, there are two types of deductibles usually used in any insurance policies as follows:

a) Percentage deductible: this type of deductible is expressed as a percentage of the amount of loss. For instance, $10 \%$ deductible means that the insurer would make it up for $90 \%$ of the whole amount of each loss and the remained $10 \%$ should be paid by insured itself. This kind of deductible is usually applied in the health insurance policies and for large individual risks and many other lines of business.

b) Straight deductible: it is stated as the first dollar amount of a given loss denoted by $D$. If the loss is less than $D$, no payment will be made by insurer and when the loss occurred is more than $D$, the insurer just pay the loss minus $D$. This kind of deductible is typically applied in property 
insurance especially for policies with lower sum insured in order to prevent small claims. This kind of insurance deductible is characterized by an indemnification function of $I(x)$ as follows (Meyer and Ormiston, 1999):

$$
I(x)= \begin{cases}0 & \text { if } X \leq D \\ (X-D) & \text { if } X>D\end{cases}
$$

i.e., the policy paying no indemnity if $X$ is less than $D$, and paying an indemnity $X-D$ if $X$ is larger than $D$. In short, the design of the optimal coverage in the case of deductible is $I(X)=$ $\max (0, X-D)$ for some scalar $D$.

\section{Utility Theory Approach}

\section{1. assumptions and notations}

In this paper, the decision maker is assumed to be risk-averse and endowed with the initial wealth of $A+L$. He will probably bear a loss of $L$ with the known probability of $\pi$ and the price or premium of $P$ will be paid by the consumer in the case of purchasing insurance. Utility function is a useful mean to demonstrate the insured preferences about consumption of the insurance in different situations and contexts. The demand for insurance is considered as the solution to the problem of maximizing a utility function which is taken from the theory of preferences under uncertainty usually referred to as the Expected Utility Theory. Under the theory of insurance demand, the consumer is modelled as having a von Neumann-Morgenstern utility function $U(W)$, which is unique up to a positive linear transformation and is at least three times continuously differentiable (Rees \& Wambach, 2008). We will examine the insured's utility function in four cases including 1) No insurance, 2) Full insurance coverage, 3) Buying insurance with $\beta \%$ of deductible in exchange for $\alpha \%$ premium discount and 4) Buying insurance with $D$ dollars deductible for $\alpha \%$ discount in premium. As the insured is supposed to be risk-averse, he has the VonNewman-Morgestern utility function which is increasing and strictly concave, reflecting the economic concept of diminishing marginal utility. In contrast, a convex utility function shows the risk-taker attitude of the insured.

\section{Problem 1: No Insurance}

In the simplest models under the buyer's budget constraint, there are two possible states of nature corresponding to the amount of loss sustained by an individual who deemed to be the consumer of an insurance product, a no loss state and a single loss event state with amount $L$. Thus, the states of nature for pure risks at the end of an insurance period are two mutually exclusive outcomes of "loss" or "No loss". If the insured does not buy any insurance coverage, his final wealth in these two cases will be as follows:

$$
W_{T}=\left\{\begin{array}{lr}
A & \pi \\
A+L & 1-\pi
\end{array}\right.
$$

where $\pi$ is the probability of the occurrence and $(1-\pi)$ is the probability of no loss state. Since the insured's decision over various states is defined under uncertainty, his utility can be represented by the expected utility function as follows (Park \& Gunter, 1990):

\begin{tabular}{lcccc}
\hline Event & Resulting Wealth & Utility & Probability & Expected Utility \\
\hline No Loss & $L+A$ & $U(L+A)$ & $1-\pi$ & $(1)(1-\pi) U(A+L)$ \\
Loss & $A$ & $U(A)$ & $\pi$ & $(2) \pi U(A)$ \\
\hline Total Expected Utility & & & & $(1)+(2)$ \\
\hline
\end{tabular}

In this way, the expected value of insured's wealth and his expected utility is given by Eq. (3): 


$$
E\left[W_{T}\right]=U^{\prime}(W)=\pi U(A)+(1-\pi) U(A+L),
$$

where $W_{T}$ denotes resulting wealth and $U^{\prime}($.$) represents the expected utility function of insured who is$ subject to uncertainty. As it is assumed that the insured is risk-averse, the utility of his expected wealth is greater than the expected utility of his wealth. Relation (4) holds for his utility function:

$$
U(\pi A+(1-\pi)(A+L)) \geq \pi U(A)+(1-\pi) U(A+L)
$$

The utility curve for the insured is depicted in Fig. 1 which normally is a concave function.

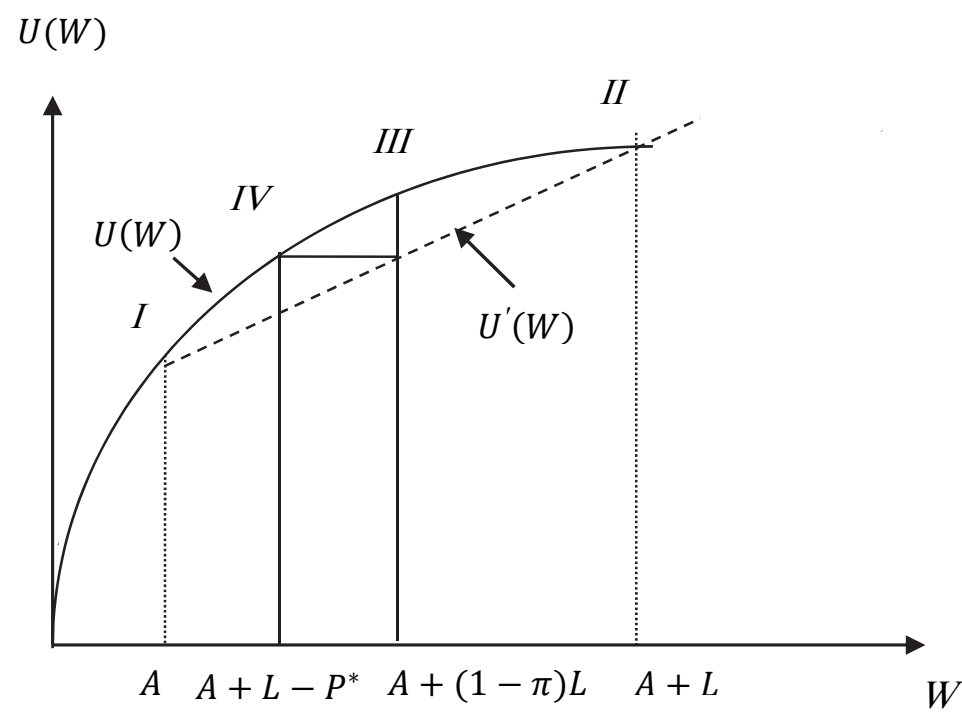

Fig. 1. Utility function in 'Insurance' and 'No Insurance' cases

Based on Eq. (4), as it is illustrated on Fig. 1, insured's utility function is the straight line mapped between two points I and II, not on the curve $U(W)$ anymore. Since uncertainty alluded to above exists and the amount of wealth is not definite, $U(W)$ definitely has higher value than the straight line. Therefore, the insured's utility function in the case of no insurance $\left(U^{\prime}(W)\right)$ is the line between the two points $I=(A, U(A))$ and $I I=(A+L, U(A+L))$ as follows:

$$
U^{\prime}(W)-U(A)=\left(\frac{U(A+L)-U(A)}{(A+L)-L}\right)(W-A) .
$$

That is, the insured's utility function will be $U^{\prime}(W)$ rather than $U(W)$ if he does not buy insurance coverage. We cannot find this new utility function in closed form and it could be calculated numerically, however the expected utility, depending on the amount of $\pi$ is somewhere on the line between points I and II.

\section{Problem 2: Full insurance coverage}

The question to be respond here is how much the insured is ready to pay for buying insurance and still remains at the same level of satisfaction i.e. the insured is indifferent between buying and not buying insurance. Since it is the maximum utility for the insured and he cannot obtain more utility, the corresponding utility is located on his initial utility function (point (IV)). This point belongs to the insured's utility function in the case of no insurance. Therefore, considering the probability of $\pi$ for occurring loss, this point is where the insured is ready to pay for buying coverage because of uncertain wealth and still remains at the same level of satisfaction. It is not necessarily coinciding with the mathematical expectation of loss and their difference would be equal to the amount of insurers' profit 
and underwriting expenses i.e. loading factor. Now if the insurer ignores this opportunity and determines lower premium, the insured will absolutely enjoy higher satisfaction through buying insurance coverage.

The minimum amount of satisfaction equals the expected value of loss and the maximum is the point, say $P^{*}$, where the utility of insured could not be less than this amount if he didn't buy insurance coverage. That is:

$$
\pi L \leq P \leq P^{*}
$$

Our purpose is to find $P^{*}$ representing as point (IV) on the wealth (W) axis in Fig. 1 . It means that $P^{*}$ is the point on horizontal axis where the utility equals to the expected value of utility in the case of no insurance.

If the insured purchases full insurance coverage and get charged $P$ as premium, his final wealth in the cases of loss and no loss will be as follows:

$$
W_{T}=\left\{\begin{array}{lr}
A+L-P-L+L, & \pi \\
A+L-P, & 1-\pi
\end{array}\right.
$$

The Eq. (7) states that with certainty, insured's wealth is $A+L-P$. So the utility function of insured will be exactly on the curve as a result of certainty about his wealth. In this case, the expected utility function takes the form of Eq. (8):

$$
U\left(W_{T}\right)=\pi U(A+L-P)+(1-\pi) U(A+L-P)=U(A+L-P)
$$

We should find $P^{*}$ so that the insured's expected utility in the case of buying insurance will not less than the insured's utility in case of no insurance:

$$
U(A+L-P) \geq \pi U(A)+(1-\pi) U(A+L)
$$

So the maximum amount of $P$, say $P^{*}$, is calculated as follows.

$$
P^{*}=A+L-U^{-1}(\pi U(A)+(1-\pi) U(A+L))
$$

If we suppose that the expected utility function is $E(W)=\operatorname{Ln}(W), P^{*}$ will be as follows:

$$
P^{*}=A+L-\left(A^{\pi} \times(A+L)^{1-\pi}\right)
$$

\section{Problem 3: Buying insurance with $\beta \%$ of deductible in exchange for $\alpha \%$ premium discount}

Suppose that there is another alternative for insured rather than buying no insurance coverage or full coverage. In this case, the insured obtains insurance coverage and accepts to retain $\beta$ percentage of loss himself in the case of an occurrence. In this case, his final wealth can be calculated as follows:

$$
W_{T}=\left\{\begin{array}{lr}
A+(1-\beta) L-(1-\alpha) P, & \pi \\
A+L-(1-\alpha) P, & 1-\pi
\end{array}\right.
$$

It is noteworthy to say that in this case, the insured's final wealth has uncertainty, hence with purchasing insurance coverage his utility is not located on $U(W)$, rather it is a line approximately under the utility curve. However, the new line is upper the previous one, i.e., Line $U^{\prime}(W)$, for no insurance case. We try to find the relationship between percentage of premium discount, $\alpha$, and amount or percentage of deductible, $\beta$. We attempt to examine the maximum amount of loss which the insured accepts to 
maintain a share of loss, $\beta$, himself in exchange for receiving specific percentage of discount $\alpha$ in his/her premium. On the other words, for paying the specific percentage of loss by insured (given value of $\beta$ ), what is the minimum amount of discount which should be paid to insured to stay at the same level of satisfaction to buy insurance with deductible. In this case the expected utility for the insured in the case of buying insurance is shown as:

$$
U^{\prime \prime}(W)=\pi U(A+(1-\beta) L-(1-\alpha) P)+(1-\pi) U(A+L-(1-\alpha) P)
$$

The maximum amount of premium $P^{*}$ is obtained in previous section. $P$ is a point where the insurer is willing to sell insurance for full coverage without any deductible which is located between $\pi L$ and $P^{*}$. Now, we determine $\alpha$ and $\beta$ so that the level of utility will not be less than this amount.

As it is clear, with purchasing insurance policy which has $\beta \%$ of deductible, the insured's expected utility should not be less than the case of no insurance coverage. So we write this inequality as follows:

$$
\begin{aligned}
& \pi U(A)+(1-\pi) U(A+L) \\
& \leq \pi U(A+(1-\beta) L-(1-\alpha) P)+(1-\pi) U(A+L-(1-\alpha) P)
\end{aligned}
$$

\section{Problem 4: Buying insurance with D dollars deductible for $\alpha \%$ discount in premium}

In some lines of business, it is common to pay first $D$ dollars of each loss by insured. It means the insured agrees if he suffers a loss less than $D$, he will not claim against the insurance company and the loss should be paid by him/herself, but if the loss is more than $D$, the insurance company will pay the amount of loss minus $D$. Now we want to examine that for what percentage of discount in premium $(\alpha \%)$, the insured agrees to pay first D dollars of loss. In this case, his wealth is equal to:

$$
W_{T}=\left\{\begin{array}{lr}
A+L-D-(1-\alpha) P, & \pi \\
A+L-(1-\alpha) P, & 1-\pi
\end{array}\right.
$$

In this case the expected utility for the insured in the case of buying insurance is shown as:

$$
U^{\prime \prime \prime}(W)=\pi U(A+L-D-(1-\alpha) P)+(1-\pi) U(A+L-(1-\alpha) P)
$$

where $W_{T}$ denotes resulting wealth and $U^{\prime \prime \prime}($.$) represents the expected utility function of insured in the$ case of buying insurance with $D$ dollars deductible. As it is clear, with purchasing insurance policy which has $D$ dollars of deductible, the insured's Expected utility should not be less than the case of no insurance. So we write this inequality as:

$$
\begin{aligned}
& \pi U(A)+(1-\pi) U(A+L) \\
& \leq \pi U(A+L-D-(1-\alpha) P)+(1-\pi) U(A+L-(1-\alpha) P)
\end{aligned}
$$

\begin{tabular}{|c|c|c|c|c|c|}
\hline \multirow[b]{2}{*}{ Row } & \multirow[b]{2}{*}{ Case } & \multicolumn{4}{|c|}{ Resulting Wealth in different cases } \\
\hline & & No Insurance & $\begin{array}{c}\text { Full Coverage } \\
\text { Insurance }\end{array}$ & $\begin{array}{c}\text { Insurance with } \beta \% \text { deductible and } \\
\alpha \% \text { Premium Discount }\end{array}$ & $\begin{array}{c}\text { Insurance with D-dollar deductible and } \alpha \% \\
\text { Premium Discount }\end{array}$ \\
\hline Loss & $\pi$ & $A$ & $A+L-P$ & $A+(1-\beta) L-(1-\alpha) P$ & $A+L-D-(1-\alpha) P$ \\
\hline No Loss & $1-\pi$ & $A+L$ & $A+L-P$ & $A+L-(1-\alpha) P$ & $A+L-(1-\alpha) P$ \\
\hline \multicolumn{2}{|c|}{$\begin{array}{l}\text { Expected Utility } \\
\text { Function }\end{array}$} & $\begin{array}{l}\pi U(A) \\
+(1-\pi) U(A \\
+L)\end{array}$ & $U(A+L-P)$ & $\begin{array}{l}\pi U(A+(1-\beta) L-(1-\alpha) P)+ \\
(1-\pi) U(A+L-(1-\alpha) P)\end{array}$ & $\begin{array}{c}\pi U(A+L-D-(1-\alpha) P)+(1-\pi) U(A \\
+L-(1-\alpha) P)\end{array}$ \\
\hline
\end{tabular}

Different decisions for these cases with the result of calculation are summarized in table 1.

\section{Table 1}

Different decisions for buying insurance and their results 


\section{Numerical Example}

In order to explain the results, we provide a simple numerical example. Suppose that insured's utility function is $U(W)=\operatorname{Ln}(w)$, and his initial wealth equals to $\$ 20,000,000$ including $A=\$ 5,000,000$ and $L=\$ 15,000,000$. In the case of full insurance coverage, for different probability of loss, we determine $P^{*}$ as shown in Table 2 using Eq. (11).

Table 2

values of $\mathrm{P}^{*}$, Expected Loss, Expected utility and insurance premium for different $\pi$

\begin{tabular}{|c|c|c|c|c|c|c|}
\hline \multirow{2}{*}{$\begin{array}{c}\pi \\
\text { (Per mill) } \\
0.5\end{array}$} & \multicolumn{2}{|r|}{$\mathrm{P}^{*}$} & \multicolumn{2}{|c|}{$\begin{array}{c}\text { Expected Loss } \\
\left(\mathrm{PP}^{*}\right)\end{array}$} & \multirow{2}{*}{$\begin{array}{c}\begin{array}{c}\text { Expected Utility In Case of } \\
\text { No Insurance }\end{array} \\
16.811\end{array}$} & \multirow{2}{*}{$\frac{\text { Insurance Premium }=P P^{*}\left(1+\text { Loading factor }{ }^{1}\right)}{\$ 8,625}$} \\
\hline & $\$$ & 13,858 & $\$$ & 7,500 & & \\
\hline 1.00 & $\$$ & 27,707 & $\$$ & 15,000 & 16.810 & $\$ 17,250$ \\
\hline 5.00 & $\$$ & 138,150 & $\$$ & 75,000 & 16.804 & $\$ 86,250$ \\
\hline 10.00 & $\$$ & 275,346 & $\$$ & 150,000 & 16.797 & $\$ 172,500$ \\
\hline 50.00 & $\$$ & $1,339,340$ & $\$$ & 750,000 & 16.742 & $\$ 862,500$ \\
\hline
\end{tabular}

${ }^{1}$ Loading factor is assumed to be $15 \%$.

In problem 3, buying insurance with specific percentage of deductible and premium discount to be considered. For different value of $\pi$ and $\beta$, assuming $U(W)=\operatorname{Ln}(w)$, we will find $\alpha$ from Eq. (14) as provided in Table 3:

Table 3

Calculation of $\alpha$ for different values of $\pi$ and $\beta$

\begin{tabular}{|c|c|c|}
\hline$\pi$ (Per mill) & $\beta(\%)$ & $\alpha(\%)$ \\
\hline \multirow{3}{*}{0.5} & 5.00 & 2.758 \\
\hline & 10.00 & 5.626 \\
\hline & 15.00 & 8.612 \\
\hline \multirow{3}{*}{1.00} & 5.00 & 2.759 \\
\hline & 10.00 & 5.628 \\
\hline & 15.00 & 8.615 \\
\hline \multirow{3}{*}{5.00} & 5.00 & 2.767 \\
\hline & 10.00 & 5.644 \\
\hline & 15.00 & 8.640 \\
\hline \multirow{3}{*}{10.00} & 5.00 & 2.776 \\
\hline & 10.00 & 5.664 \\
\hline & 15.00 & 8.670 \\
\hline \multirow{3}{*}{50.00} & 5.00 & 2.855 \\
\hline & 10.00 & 5.824 \\
\hline & 15.00 & 8.919 \\
\hline
\end{tabular}

The values of $\alpha$ in Table 3 illustrates that varying probability of loss does not have any considerable effect on amount of $\alpha$. These amounts of $\alpha$ are the minimum percentages of discount which the insured is ready to accept for the given $\beta$. In problem 4 , which is about buying insurance with specific amount of deductible and premium discount, For different value of $\pi$ and $D$, assuming $U(W)=\operatorname{Ln}(w)$, we will find $\alpha$ from Eq. (17) as Table 4.

Table 4

Calculation of $\alpha$ for different values of $\pi$ and $D$

\begin{tabular}{|c|c|c|c|c|c|}
\hline$\pi$ (Rate Per mill ) & $\mathrm{D}(\$)$ & $\alpha(\%)$ & $\pi$ (Per mill) & $\mathrm{D}(\$)$ & $\alpha(\%)$ \\
\hline \multirow{3}{*}{0.5} & 250,000 & 0.908 & \multirow[t]{3}{*}{10.00} & 250,000 & 0.908 \\
\hline & 500,000 & 1.827 & & 500,000 & 1.839 \\
\hline & $1,000,000$ & 3.701 & & $1,000,000$ & 3.726 \\
\hline \multirow{3}{*}{1.00} & 250,000 & 0.908 & \multirow[t]{3}{*}{50.00} & 250,000 & 0.939 \\
\hline & 500,000 & 1.827 & & 500,000 & 1.891 \\
\hline & $1,000,000$ & 3.700 & & $1,000,000$ & 3.831 \\
\hline \multirow{3}{*}{5.00} & 250,000 & 0.908 & & & \\
\hline & 500,000 & 1.827 & & & \\
\hline & $1,000,000$ & 3.713 & & & \\
\hline
\end{tabular}


Table 4 yields almost the same conclusion as Table 3 . It is again obvious that the probability of loss have minor effects on the discount amount of $\alpha$. However, the higher proportion of loss paid by insured, the higher discount is expected to receive. These values of $\alpha$ are the minimum percentages of discount which insured is ready to receive and still have satisfaction for paying first $D$ dollars of each loss.

\section{Conclusion}

In this paper, the relationship between different type of deductible with varying amounts and premium discount has been examined and the lower bound for premium discount was calculated for each case. These boundaries reveal that in exchange for the specific percentage/ amount of deductible, the insured is ready to pay from each loss and still yields satisfaction from buying insurance coverage.

The expected utility for insured in four cases of no insurance, full insurance coverage, insurance with $\beta \%$ deductible and insurance with a D-dollar deductible are calculated given the utility function.

Furthermore, assuming the insured to be risk-averse and to have increasing and concave utility function, we have considered the insured's utility function to be $\operatorname{Ln}(W)$. The result of numerical example has shown that in most of the cases which are very close to real situations, the maximum premium that the insured is ready to pay and still have satisfaction is almost twice the expected loss.

Furthermore, the percentage of $\alpha$ is always less than the percentage of given $\beta$. It means that in exchange for receiving smaller percentage of discount compared to the percentage of deductible, the insured still have utility to pay given portion of loss. In other words, the insurance company would not need to give any discount higher than $\beta$ to acquire customers. This result holds true for first $D$ dollars of each loss. So, even with the little percentage of discount, the insured is ready to pay some portion of each loss himself and still remains satisfactory.

The other interesting result is that the change in probability of loss i.e. insurance rate, would have ignorable effect on the amount of receivable discount by insured in both cases of straight deductible and percentage deductible.

\section{References}

Aase, K. K. (2010). Pareto optimal insurance policies in the presence of administrative costs. $N H H$ Dept. of Finance \& Management Science Discussion Paper, (2010/7).

Arrow, K. J. (1971). Essays in the theory of risk-bearing. Markharm Publishing Company, Chicago, Illinois.

Arrow, K. J. (1974). Optimal insurance and generalized deductibles. Scandinavian Actuarial Journal, 1974(1), 1-42.

Arrow, K. J. (1965). Uncertainty and the welfare economics of medical care: reply (the implications of transaction costs and adjustment lags). The American economic review, 55(1/2), 154-158.

Barniv, R., Schroath, F., \& Spivak, A. (1999). The relationship between deductibles and wealth: The case of flood insurance. Journal of Insurance Issues, 78-97.

Blazenko, G. (1985). The design of an optimal insurance policy: note. The American Economic Review, 75(1), 253-255.

Borch, K. (1975). Optimal insurance arrangements. Astin Bulletin, 8(03), 284-290.

Chitgopekar, S. S. (2000). Relationship between Deductibles and Expected Payouts for Insurance Policies.

Dana, R. A., \& Scarsini, M. (2007). Optimal risk sharing with background risk. Journal of Economic Theory, 133(1), 152-176.

Demers, F., \& Demers, M. (1991). Increases in risk and the optimal deductible. The Journal of Risk and Insurance, 58(4), 670-699. 
Doherty, N. A., \& Schlesinger, H. (1983). The optimal deductible for an insurance policy when initial wealth is random. Journal of Business, 555-565.

Dreze, J. H. (1981). Inferring risk tolerance from deductibles in insurance contracts. Geneva Papers on Risk and Insurance, 48-52.

Eeckhoudt, L., Gollier, C., \& Schlesinger, H. (1991). Increases in risk and deductible insurance. Journal of economic Theory, 55(2), 435-440.

Gollier, C. (1987). The design of optimal insurance contracts without the nonnegativity constraint on claims. The Journal of Risk and Insurance, 54(2), 314-324.

Gollier, C. (1996). Optimum insurance of approximate losses. Journal of Risk and Insurance, 369-380.

Gollier, C. (2003). To insure or not to insure? : an insurance puzzle. The Geneva Papers on Risk and Insurance Theory, 28(1), 5-24

Gollier, C., \& Schlesinger, H. (1996). Arrow's theorem on the optimality of deductibles: a stochastic dominance approach. Economic Theory, 7(2), 359-363.

Gollier, C., \& Schlesinger, H. (1995). Second-best insurance contract design in an incomplete market. The Scandinavian Journal of Economics, 123-135.

Huberman, G., Mayers, D., \& Smith Jr, C. W. (1983). Optimal insurance policy indemnity schedules. The Bell Journal of Economics, 415-426

Kunreuther, H., \& Pauly, M. V. (2006). Insurance decision-making and market behavior. Now publishers Inc.

Meyer, J., \& Ormiston, M. B. (1999). Analyzing the demand for deductible insurance. Journal of Risk and Uncertainty, 18(3), 223-230.

Park, C. S., \& Sharp-Bette, G. P. (1990). Advanced engineering economics. Wiley

Raviv, A. (1979). The design of an optimal insurance policy. The American Economic Review, 69(1), 84-96.

Rees, R., \& Wambach, A. (2008). The microeconomics of insurance. Now Publishers Inc.

Schlesinger, H. (1981). The optimal level of deductibility in insurance contracts. Journal of risk and insurance, 465-481.

Shavell, S. (1979). On moral hazard and insurance (pp. 280-301). Springer Netherlands.

Schlesinger, H. (2000). The theory of insurance demand. In Handbook of insurance (pp. 131-151). Springer Netherlands. Revised, in G. Dionne, Handbook of Insurance, February 2012. 